\title{
Trace Analyses of Hydrocarbons to Understand the Fate of these Contaminants in Aquifers
}

\author{
D. Blanchet ${ }^{1}$, Y. Benoit ${ }^{1}$ and F. Haeseler ${ }^{1}$ \\ 1 Institut français du pétrole, Département Biotechnologie et Chimie de la Biomasse, \\ 1 et 4, avenue de Bois-Préau, 92852 Rueil-Malmaison Cedex - France \\ e-mail: denis.blanchet@ifp.fr - yves.benoi†@ifp.fr - frank.haeseler@ifp.fr
}

\begin{abstract}
Résumé - Analyse des traces d'hydrocarbures pour la compréhension du devenir de ces contaminants dans les aquifères - Les sites et sols pollués par les activités industrielles font l'objet d'une prise de conscience croissante depuis une vingtaine d'années. Ces pollutions reflètent parfois plus d'un siècle d'activités industrielles. Le passif environnemental lié à ces activités peut être lourd, en particulier sur les écosystèmes et surtout les ressources en eau. Aujourd'hui, les autorités administratives ont mis en place des outils réglementaires et méthodologiques (guides ESR ERD version 0, juin 2000) pour traiter, de manière pragmatique, le problème environnemental majeur que posent les sites pollués et réparer les erreurs du passé. Ces outils, basés sur une évaluation des risques prenant en compte l'eau et la santé, permettent d'ajuster les réponses en matière de réhabilitation des sites en fonction notamment de leur usage actuel ou futur. Dans ce contexte, la compréhension des mécanismes de transfert de la pollution d'un sol vers l'eau est essentielle pour évaluer qualitativement et quantitativement l'impact sur la ressource en eau. En effet, de nombreux processus, qu'ils soient physiques, chimiques et surtout biologiques, sont susceptibles d'affecter la quantité et surtout la composition de la pollution. Dans cet article sont exposés des travaux portant sur des approches méthodologiques permettant d'appréhender le devenir biologique et la forme sous laquelle se trouvent les hydrocarbures dans l'eau. Les cas étudiés concernent des pollutions réelles; l'une par une essence, générant un panache d'hydrocarbures monoaromatiques et l'autre par goudron de houille générant une pollution par hydrocarbures aromatiques polycycliques.
\end{abstract}

\footnotetext{
Abstract - Trace Analyses of Hydrocarbons to Understand the Fate of these Contaminants in Aquifers - In recent years, it has become increasingly evident that the problems related to soil and groundwater pollution are of major concern in industrial countries. The persistence of contamination in the environment and the toxicity of pollutants have led to important investigations and researches in this field. The competent authorities have set up regulations and methodologies to face the problems of contaminated sites in order to repair the errors of the past in a pragmatic way. These are risk based tools and take into account both water resources and health. They allow the treatment to be adjusted to the future use of the site. In this context, understanding the mechanisms of pollution transfer from the soil to the water phase becomes crucial to evaluate the quantitative and qualitative impact on the water resources. As a matter of fact, numerous processes—physical, chemical and in particular biological - are susceptible to affect the quantity and particularly the composition of the contaminant. This paper will present methodologies allowing the biological fate and the physical state of hydrocarbons in water to be perceived. Results from two real cases will be presented: the first one contaminated with gasoline and
} 
generating an important plume of dissolved monoaromatic compounds and the other one contaminated with coal tars inducing a pollution with polyaromatic hydrocarbons.

\section{INTRODUCTION}

In the recent years, it has become increasingly evident that the problems related to soil and groundwater pollution are of major concern in industrial countries. The persistence of contamination in the environment and the toxicity of polluting compounds have led to important investigations and researches in this field. The competent authorities have set up regulations and methodologies to face the problems of contaminated sites in order to repair the errors of the past in a pragmatic way. These tools are becoming increasingly risk-based and take into account both water resources and health. They allow the treatment to the use of the site to be adjusted. In this context, understanding the mechanisms of pollution transfer from the soil to the water phase becomes crucial to evaluate the quantitative and qualitative impact on the water resources. As a matter of fact, numerous processes-physical, chemical and in particular biologicalare susceptible to affect the quantity and particularly the composition of the contaminant. This paper will present methodologies allowing the biological fate and the physical state of hydrocarbons in water to be perceived. Results from two cases will be presented: the first one contaminated with gasoline and generating an important plume of dissolved monoaromatic compounds and the other one contaminated with coal tars inducing a pollution with polyaromatic hydrocarbons.

Natural attenuation is increasingly considered as an alternative to more active measures for the remediation of contaminated sites. Intrinsic biodegradation represents the key process in the natural attenuation going on in the gasoline contaminated site presented in this article. In the case of petroleum distillation products like gasoline, the selective dissolution process leads to a groundwater pollution mainly characterized by monoaromatic compounds including BTEX (Benzene, Toluene, Ethybenzene and Xylenes) and others substituted monoaromatics. Physiologically diverse microbial communities including nitrate-, sulfate-, ironreducers and methanogens present the ability to degrade aromatic compounds under strict anaerobic conditions but the degradation is typically much slower than under aerobic conditions. This anaerobic biodegradation has also been established for aliphatic compounds (Van Hamme et al., 2003; Widdel et Rabus, 2001), but due to very low kinetics, is not relevant for subsurface active processes. In this site, the pollutant profile alteration is expected to be strongly influenced by aerobic metabolism.

Polycyclic aromatic hydrocarbons (PAH) are pollutants that cause concern because of their genotoxic properties (Kramer and Van der Heijden, 1990) and their environmental importance led the US Environmental Protection Agency (EPA) to include 16 unsubstituted PAH in the priority list of pollutants (Keith and Telliard 1979). At coal pyrolysis sites such as former manufactured gas plant (MGP) sites, PAH are present as components of coal tar (Haeseler et al., 1999a) and constitute persistent pollutants. It is well known that only partial biodegradation of PAH could be achieved in MGP soils even under optimized conditions (Thiem et al., 1997). In terms of risk assessment, an important question that arises is whether residual PAH present in the coal tar phase can still be transferred to water or if they can be considered as nonaccessible and in consequence present a negligible potential for groundwater contamination (Haeseler et al., 1999b). The aim of the developed methodology was to evaluate the impact on water of PAH contaminating soils originating from former MGP sites. This methodological approach developed for soil leaching experiments, including (biotic and abiotic) transfer, filtration and chromatographic analysis, was applied on various soil samples and on groundwater samples for the evaluation of PAH transfer to water.

These results highlight for both monoaromatic and polyaromatic hydrocarbons the importance of understanding the contamination and its environment. The examples presented in this article show the importance for laboratory and fieldwork of avoiding artefacts such as: biodegradation, presence of colloids, evaporation, etc. In other words, these results demonstrate the importance of the sample preparation in the environmental field.

\section{MATERIAL AND METHODS}

\subsection{Monoaromatic Hydrocarbons}

\subsubsection{Site Investigation}

Water samples were collected from a grid of 30 wells. For both microbiological and analytical studies, sterile glass bottles with watertight Teflon coated caps were filled up with water avoiding any gas phase and stored immediately at $4{ }^{\circ} \mathrm{C}$ in the dark. In the laboratory, a fraction of each water sample was dispensed in an anaerobic chamber into vials that were sealed with butyl rubber stoppers. Gas phase in the vials was exchanged with $\mathrm{N}_{2}$, outside the chamber, using a gazing manifold. These vials were used for anaerobic microbiology. The bottles and vials were stored at $4{ }^{\circ} \mathrm{C}$ until use.

\subsubsection{Biodegradation in Aerobic Conditions}

Experiments were performed in Erlenmeyer flasks with a working liquid volume of $75 \mathrm{ml}$, and a gas phase (air) of 
$45 \mathrm{ml}$, providing enough $\mathrm{O}_{2}$ for total carbon oxidation. The working liquid was composed by $25 \mathrm{ml}$ of a gasoline/water phase contact supplying dissolved hydrocarbons, $25 \mathrm{ml}$ of water samples collected from observation wells used as inoculum and $25 \mathrm{ml}$ of mineral salt solution. The flasks were closed with Teflon butyl stoppers. Abiotic control received $250 \mu \mathrm{l}$ of $\mathrm{a}_{2} \mathrm{SO}_{4} 4 \mathrm{~N}$ solution. Essay and control (both triplicate) prepared for each point of the kinetic were gently shaken at $20^{\circ} \mathrm{C}$.

\subsubsection{Analytical Methods}

Soluble hydrocarbons were analyzed on essay and control flasks. The analytical method combined SPME (solid phase micro extraction) technique with gas chromatography (GC) equipped with a flame ionization detector (FID). The SPME headspace procedure involved a fiber coated with a $100 \mu \mathrm{m}$ thickness film of polydimethylsiloxane phase according to the methodology described by Pawliszyn (1999). The use of HydroCARB ${ }^{\circledR}$ software based on a retention index principle allowed detailed information at low concentrations on about 200 individual hydrocarbons (Ropars M., personal communication). External calibration was done using a commercial mixture of identified compounds (502/524 Volatile Organic Calibration Mix, Supelco).

\subsection{Polyaromatic Hydrocarbons}

\subsubsection{Soil Preparation}

All soil samples originated from different contaminated former MGP sites. After thorough homogenization, the sub 2-mm soil fraction was used for analytical characterization and for the leaching studies.

\subsubsection{Soil Analysis}

PAH extraction from soil samples was carried out with a cyclohexane-acetone $(85 / 15, \mathrm{v} / \mathrm{v})$ mixture. PAH analyses in solvent extracts were carried out by GC-FID. The operating and calibration conditions used were as previously described (Haeseler et al. 1999a).

\subsubsection{Soil Leaching}

The method used for soil leaching was adapted from the standard method (DIN 38414 part 4). $100 \mathrm{~g}$ (dry weight) of soil were shaken with 11 of distilled water in 21 glass flasks for 24 hours on a rotary shaker at $10 \mathrm{rpm}$.

\subsubsection{Leachate and Groundwater Analyses}

PAH in leachates were analyzed by high performance liquid chromatography (HPLC). PAH were analyzed after liquidliquid extraction of duplicate 50 or $100 \mathrm{ml}$ samples with $1 \mathrm{ml}$ cyclohexane. The solvent was then evaporated to near dryness and replaced by acetonitrile. As some loss of volatile
PAH (naphthalene, acenaphthylene and acenaphthene) occurred during cyclohexane evaporation, the concentration of these PAH was determined by direct analysis of nonextracted leachate samples mixed with acetonitrile $(1 \mathrm{v} / 1 \mathrm{v})$. HPLC analysis of PAH was performed with a gradient pump Series 410 equipped with an autosampler ISS 200 (Perkin Elmer) using a Supelcosil LC-PAH column (Bellefonte). The PAH were quantified by UV detection with a diode array detector (PDA 996, Waters) at the specific absorption wavelength of each compound and with a fluorimeter (model 470 , Waters) at specific excitation/emission wavelengths.

\section{RESULTS}

\subsection{Monoaromatic Hydrocarbons}

Site 1 is a large fuel storage site that had been contaminated in 1962 with about 10 to $20 \mathrm{~m}^{3}$ of Mogaz: a particular gasoline. Due to fractured bedrock, the oil phase was nearly not subjected to weathering. This ensured for over 40 years a limited but continual release of hydrocarbons in groundwater. Major upwelling events of the groundwater table (more than $14 \mathrm{~m}$ ) were due to a hilly topography.

About 5 tons of the mobile gasoline phase were removed by pumping over a period of 5 years. Plume expansion (approximately $1 \mathrm{~km}$ length) and dissolved hydrocarbons have been monitored through a grid of 30 wells mostly in lines perpendicular to the plume flow direction.

The oil phase recovered from this site contained $26 \%$ $n$-paraffins, 35\% iso-paraffins, $17.4 \%$ naphthenes, $11.6 \%$ aromatics, $9.3 \%$ olefins, $0.5 \% \mathrm{C} 15+$ hydrocarbons and less than $0.5 \%$ of unidentified compounds. This composition, in particular the presence of olefins, the low content of aromatics and the high content of normal paraffin, clearly indicate that this contaminant is an old gasoline: the Mogaz from 1962 reported as having been released in February of that year. The presence of light hydrocarbons (olefins with less than 5 carbon atoms) thus indicates that the oil phase was only subjected to a limited volatilisation and solubilisation. The most important hydrocarbons present in this oil phase regarding its impact on the groundwater are the most water soluble monoaromatic hydrocarbons illustrated in the Figure 1.

A gasoline/water phase contact was prepared using free oil phase recovered from the site. The hydrocarbons transferred to the aqueous phase in this laboratory experiment showed a similar profile to the hydrocarbons present in the plume of the site. The concentration obtained in the sample originating from the site in the heart of the hotspot are about a third those measured in the laboratory experiment. These data are presented in Figure 2. The hydrocarbons transferred in the aqueous phase are mainly monoaromatic compounds 


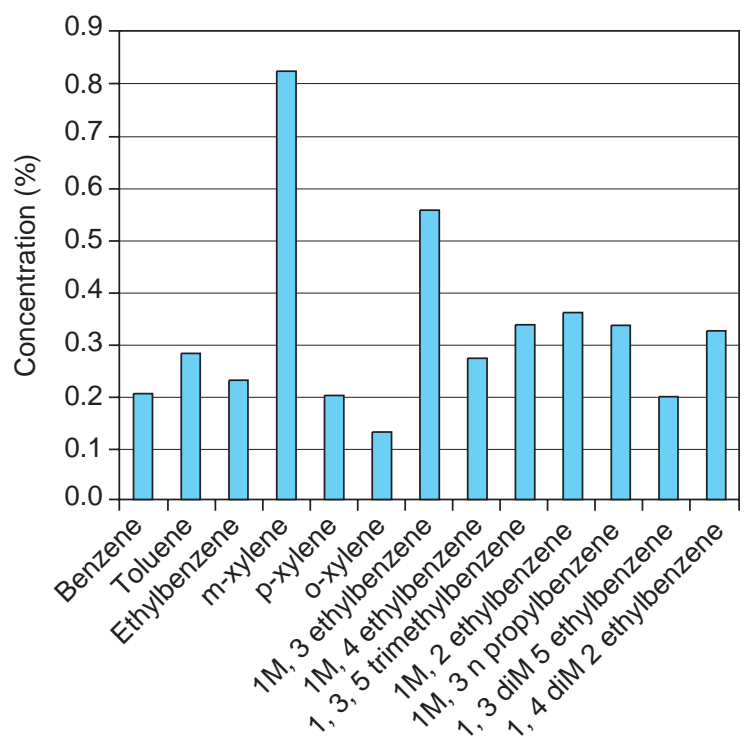

Figure 1

Composition of the major monoaromatic compounds present in the oil phase contaminating the site.

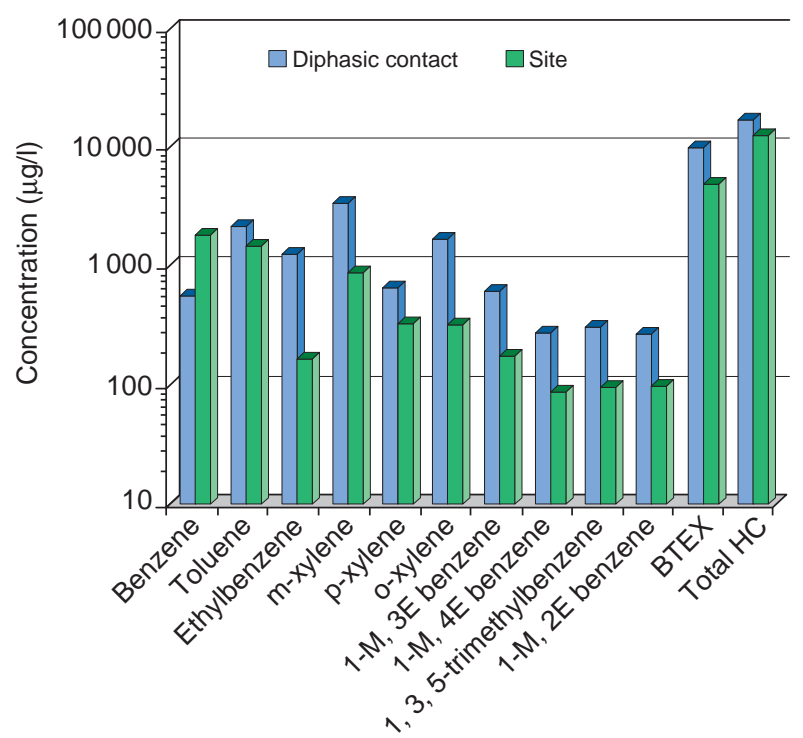

Figure 2

Concentration of dissolved hydrocarbons in the aquifer sampled right under the contamination source and in the gasoline/water contact using free oil recovered on the site.
(73\% of total hydrocarbons). Twenty major compounds represent $91 \%$ of the aromatic fraction.

Figure 3 shows the plume of dissolved hydrocarbons in the aquifer downstream of the contaminated hot spot. This plume appears to be very long: about $1300 \mathrm{~m}$ for the hydrocarbon concentration above drinking water concentration $(>10 \mu \mathrm{g} / \mathrm{l})$.

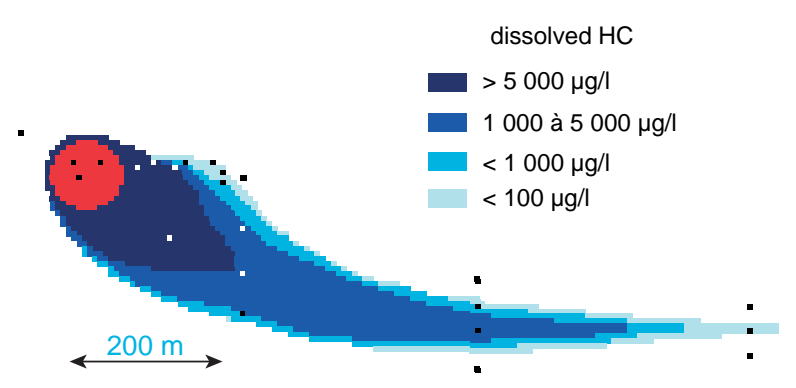

Figure 3

Plume of dissolved hydrocarbons in the aquifer downstream of the contamination source (in red: oil phase present in the porous medium; black dots: monitoring wells).

The results of the detailed hydrocarbon analyses from water samples are presented in the Figure 4. The samples have been taken from wells located in the hydrocarbon plume at increasing distances from the contaminated soil $(0$, $50,150,700$ and $1300 \mathrm{~m}$ ). These results show that the concentration of most of the main hydrocarbons decreases with increasing distance from the contamination source. The efficiency of the analytical method used allowed the biodegradation of the hydrocarbons dissolved in the plume to be evaluated through the evolution of ratios of specific identified compounds. For compounds presenting comparable octanol-water partition coefficients, significant differences in disappearance velocities indicate that intrinsic biodegradation occurs. In the present case, 8 of the 11 preponderant compounds are very rapidly biodegraded. On the other hand, 4 compounds: 1,3,5-trimethylbenzene, 1-methyl, 2-ethylbenzene, 1,2,3-trimethylbenzene and $n$-propylbenzene, are still persistent (less than 50\% decrease) at $700 \mathrm{~m}$.

The persistence of recalcitrant compounds showed that the decreasing pollutant concentrations (from $30 \mathrm{mg} / \mathrm{l}$ to $\mu \mathrm{g} / \mathrm{l}$ range) with increasing plume length, particularly in the first $700 \mathrm{~m}$, were mostly attributed to biodegradation. As a consequences only limited dilution and dispersion occurred in this part of the aquifer. Dilution mechanisms appear in the aquifer after the $700 \mathrm{~m}$ line due to lateral water fluxes going down in the valley.

The oxygen concentration in the plume is very low, and only nitrate is present as alternative electron acceptor (maximal concentration of $15 \mathrm{mg} / \mathrm{l}$ in the upstream). All the available electron acceptors are depleted in the plume until the well located at $700 \mathrm{~m}$ downstream of the contamination source. The electron acceptors potentially used by the autochthonous microflora mainly originate from lateral water 


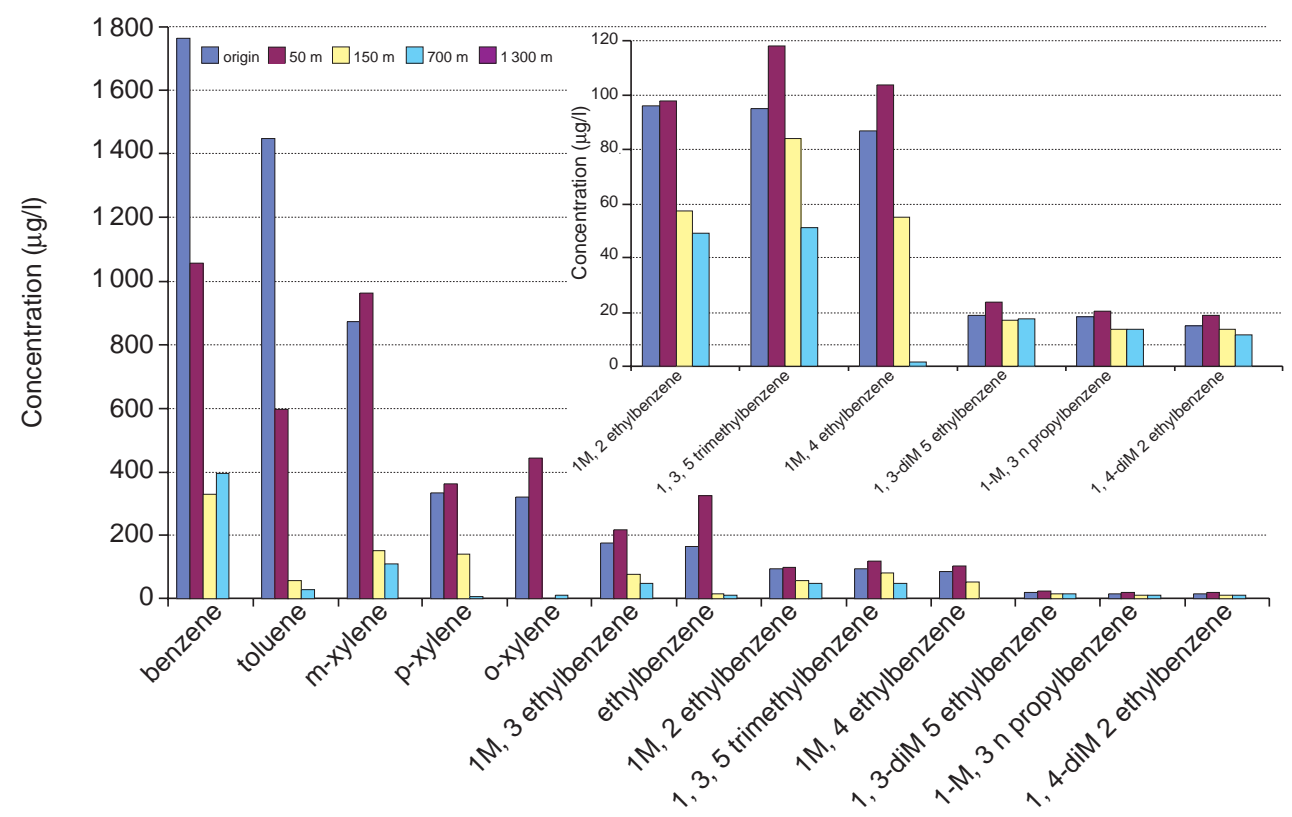

Figure 4

Concentration of dissolved hydrocarbons in the plume at increasing distances from the contamination source.

fluxes arriving in the thalweg where the plume is located. These water fluxes provide electron acceptors necessary to the biodegradation of the hydrocarbons present in the plume.

The potential of biodegradation of the indigenous microorganisms was investigated in the laboratory under aerobic conditions. The aqueous phase obtained from the diphasic contact (Fig. 2) was used as hydrocarbon source. This approach allowed on one hand to study the biodegradability of individual components that are not always available as commercial products, and on the other hand to have roughly the same relative proportion of individual compounds as in the polluted groundwater (e.g. Figs. 2, 5 and 6). The differences observed between the concentration in the groundwater and in the water obtained after a contact with the oil are probably due to differences in the oil composition (volatilisation and solubilisation). This approach gives more realistic kinetic information about the biological removal of the pollution and is furthermore suitable to evaluate the substrate interactions observed by Chang et al. (1993) and Oh et al. (1994) and susceptible to lead to inhibition e.g. cometabolism. These authors have shown that hydrocarbon mixtures may affect the rates of disappearance as well as the overall behaviour of these compounds during biological degradation. Therefore it is preferable to study the degradation of the whole water-soluble fraction of the gasoline, rather than individual hydrocarbons.

The results of biodegradation tests carried out in the laboratory are presented in the Figure 7 . These tests were carried out under aerobic conditions at $20^{\circ} \mathrm{C}$ during 32 days.
Polluted water collected on observation wells at $700 \mathrm{~m}$ from the contamination source was used as inoculum. Due to low charge of micro-organisms in the plume and limited initial concentration of the individual components (between 20 to $1000 \mu \mathrm{g} .1^{-1}$ ) reflecting the thermodynamic equilibrium between the oil and the water phase, the highest attention was given to validate the biodegradation especially for weak degradation levels. Abiotic loss of hydrocarbons, and especially of volatile aromatics, was evaluated on controls for each point of the kinetic. The BTEX (except o-xylene), and three other substituted benzene compounds, 1-methyl, 3-ethylbenzene, 1-methyl, 4-ethylbenzene and 1.4-dimethyl, 2-ethylbenzene, are biodegraded. This last compound with an initial concentration of $20 \mu \mathrm{g} . \mathrm{l}^{-1}$ illustrates the sensitivity of the methodological approach including the analytical method combining SPME/GC and HydroCARB ${ }^{\circledR}$ software. Compounds such as 1,3,5-trimethylbenzene and 1-methyl, 2-ethylbenzene, present in relatively high proportion in the aromatic fraction (90-100 $\mu \mathrm{g} . \mathrm{l}^{-1}$ ) are not biodegraded in this test, in good agreement with the evolution of these compounds in the plume. The degradation of gasoline by a microflora originating from a urban waste water treatment plant was investigated by Solano-Serena et al. (1999). They found that all the aromatic compounds usually considered as recalcitrant were entirely biodegraded but with a high inoculum level (10 mg dry matter per essay). Interestingly, the two components not completely biodegraded in these optimised conditions were also 1-methyl, 2-ethylbenzene and 1,3,5-trimethylbenzene. 

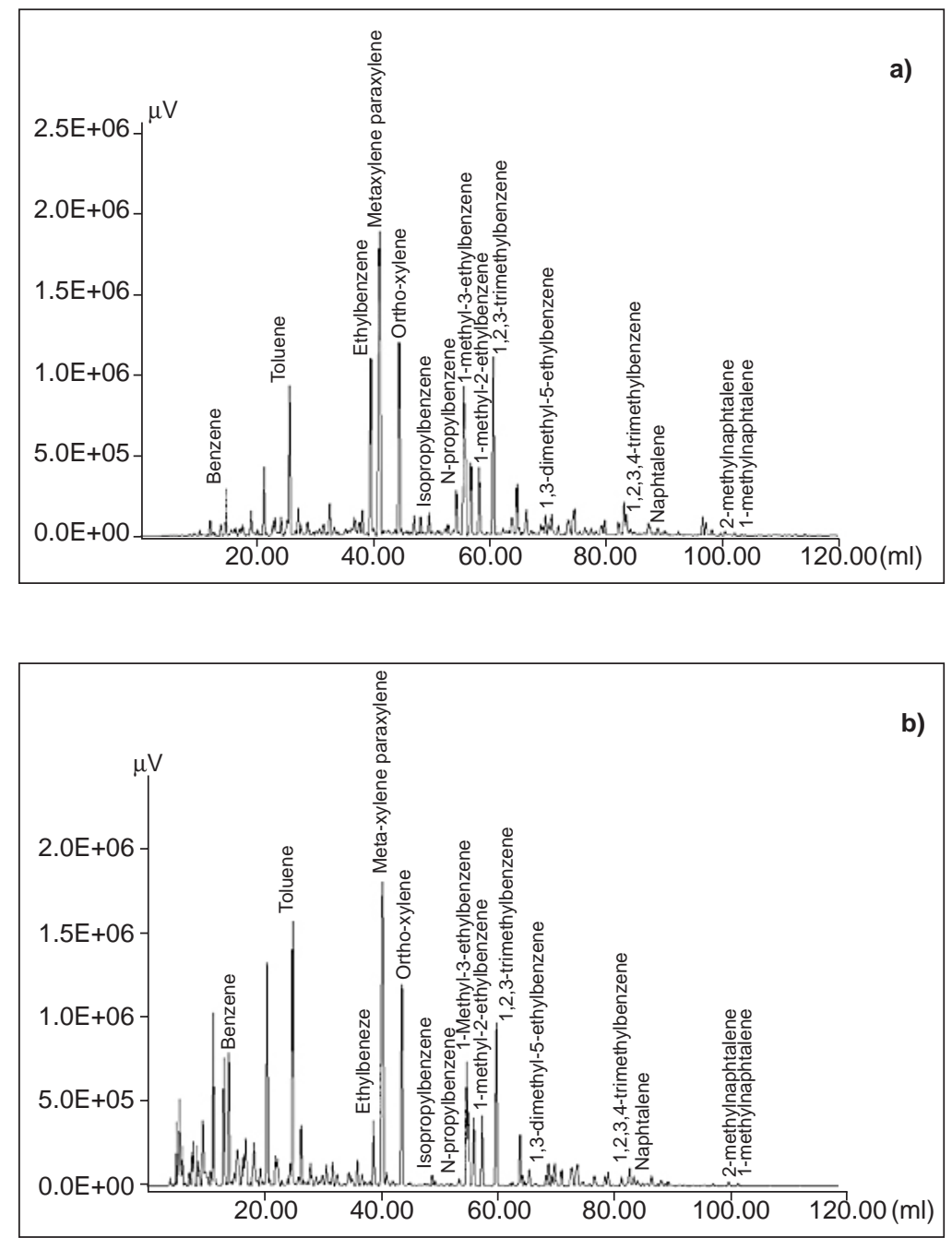

Figure 5

Gas chromatograms of the dissolved hydrocarbons: a) groundwater sampled in the hot spot area; b) water after a diphasic contact with the oil phase sampled in the hot spot.

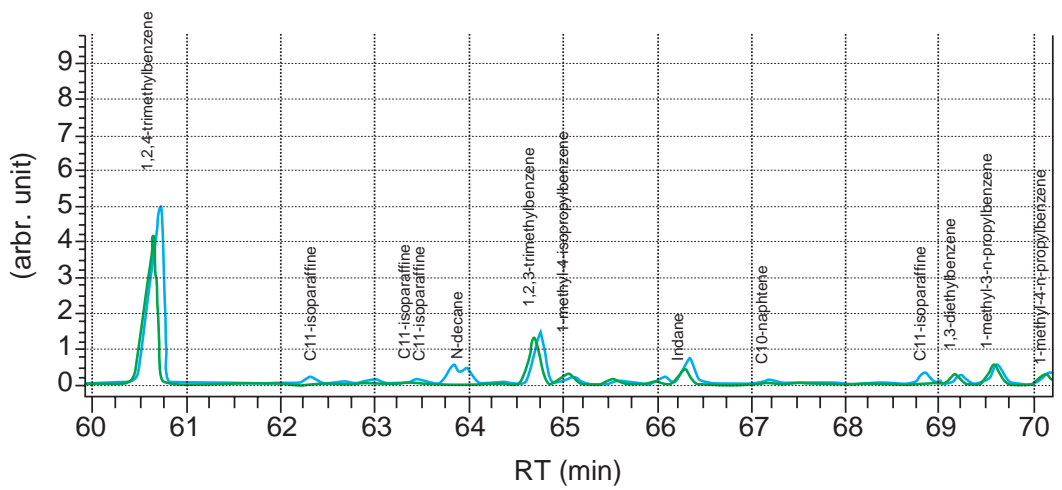

Figure 6

Zoom in the gas chromatograms presented in Figure 5: red): groundwater in the hot spot area; blue: water after a diphasic contact with the oil phase sampled in the hot spot. 


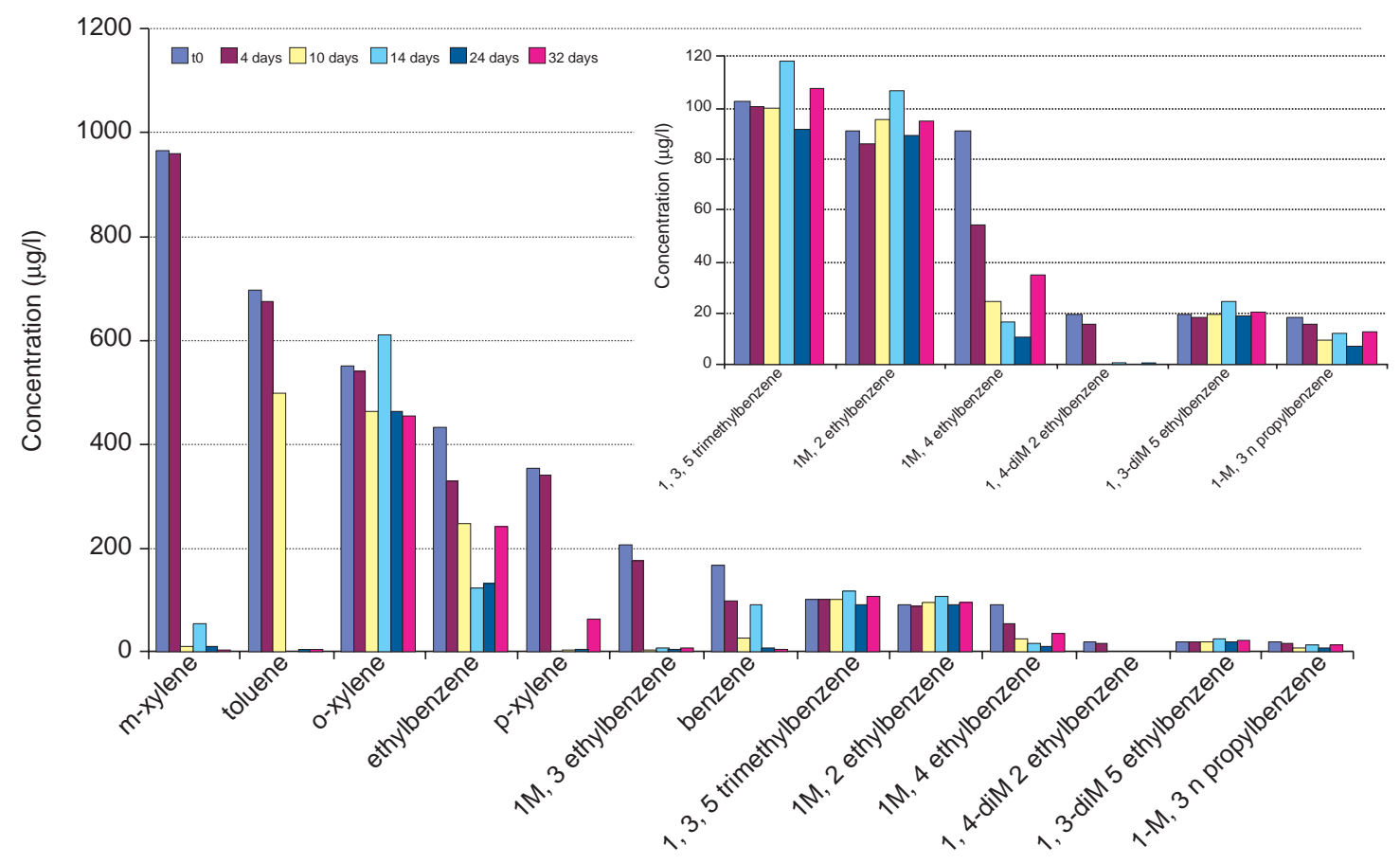

Figure 7

Evolution of hydrocarbon concentration in aerobic biodegradation experiments.

\subsection{Polyaromatic Hydrocarbons}

The PAH leachates of former MGP soil was based on a treatment in a rotary shaker which generated coarse particles. The analytical method used for the quantification of the dissolved PAH included a liquid-liquid extraction with cyclohexane to improve detection levels, especially for heavy PAH (4 and 5+6 cycles). So the complete removal of the particles became a key question for the evaluation of the truly dissolved PAH fraction in the water phase. Centrifugation was not convenient because of the limited volumes obtained (at least $200 \mathrm{ml}$ samples were required) and the risk to remobilize particles while withdrawing the water (Bethmann et al., 1996). Filtration was thus preferred. Two membranes with a calibrated porosity of $0.45 \mu \mathrm{m}$ were tested for PAH adsorption: Regenerated cellulose (Schleicher \& Schuell) and Mitex (Millipore). The membranes were set on a tefloncoated stainless steel filter holder (Toxic Waste Filter Holder, $142 \mathrm{~mm}$, Millipore). Glass fiber filters were not suitable because their porosity is not calibrated and the lowest porosity available was $0.7 \mu \mathrm{m}$.

Table 1 shows the recovery ratios of synthetic PAH dissolved in distilled water after filtration on Regenerated cellulose and Mitex membranes. Naphthalene was not retained by both filters but the other PAH exhibited various retention ratios rising up to more than $99 \%$. The retention yield of Mitex membrane was higher than that of regenerated cellulose for all the PAH considered. For both membranes it appears that the lower the PAH solubility, the higher the retention on the membrane.

TABLE 1

Recovery ratios of dissolved synthetic PAH after water filtration on different membrane types: Regenerated Cellulose (RC) and Mitex

\begin{tabular}{l|c|c|c}
\hline & $\begin{array}{c}\text { Initial } \\
\text { concentration } \\
(\mu \mathrm{g} / \mathrm{l})\end{array}$ & \multicolumn{2}{|c}{$\begin{array}{c}\text { Recovery ratios } \\
(\%)\end{array}$} \\
& 2.9 & 101 & 122 \\
\hline Naphthalene & 2.8 & 63 & $<0.1$ \\
\hline Acenaphthylene & 2.7 & 107 & 53 \\
Acenaphthene & 2.5 & 71 & 56 \\
Fluorene & 2.4 & 49 & 25 \\
Phenanthrene & 1.8 & 36 & 13 \\
Anthracene & 2.0 & 41 & 6 \\
\hline Fluoranthene & 2.2 & 31 & 4 \\
Pyrene & 1.5 & 7.1 & $<0.1$ \\
Benz(a)anthracene & 1.4 & 6.0 & $<0.1$ \\
Chrysene & 1.4 & 1.1 & $<0.1$ \\
\hline Benzo(b)fluoranthene & 1.3 & 0.5 & $<0.1$ \\
Benzo(k)fluoranthene & 1.3 & 0.8 & $<0.1$ \\
Benzo(a)pyrene & 1.4 & 0.3 & $<0.1$ \\
Dibenz(a,h)anthracene & 1.3 & 0.6 & $<0.1$ \\
Benzo(g,h,i)perylene & 1.2 & $<0.1$ & $<0.1$ \\
Ideno(c,d)pyrene & & & \\
\hline
\end{tabular}

RC: Regenerated Cellulose 


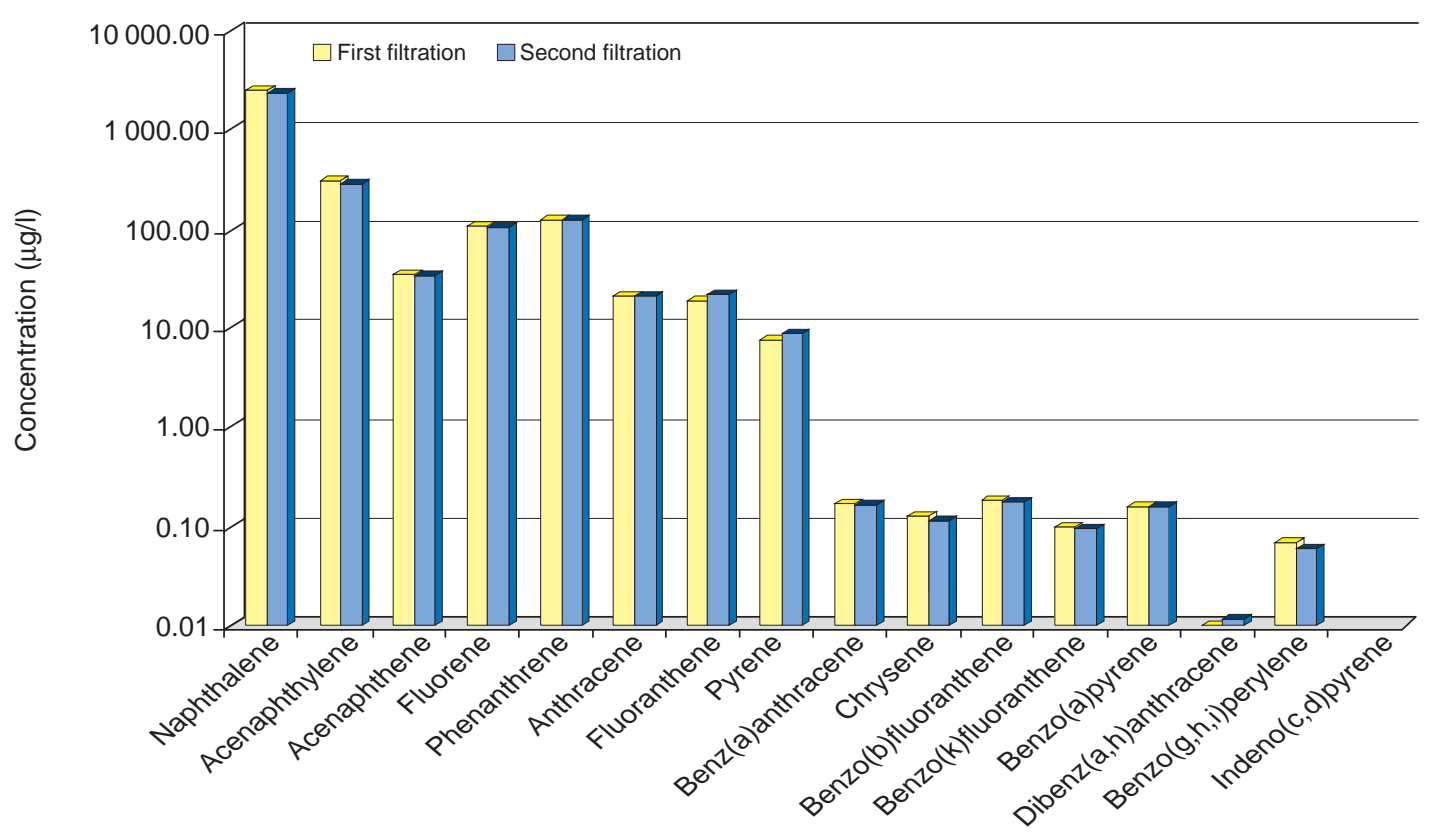

Figure 8

PAH concentrations in an aqueous soil leachate solution after two successive filtrations on a regenerated cellulose membrane.

The retention of PAH on regenerated cellulose membrane has also been studied on leachates from polluted soils and on water samples both originating from a former gas work plant. The quite similar PAH concentrations in the leachates after two successive filtrations (Fig. 8) strongly suggested the presence of colloidal bounded PAH.

Table 2 shows the PAH concentration in groundwater of a former MGP site without and with a filtration on a regenerated cellulose membrane. It appears that high concentrations of PAH associated to coarse particles are present in the groundwater. These coarse particles probably not reflect natural transport mechanisms and should be removed by filtration prior to analysis in order not to overestimate the PAH concentration in the groundwater.

For many different soil samples, a significant PAH biodegradation by the autochthonous microflora was observed during leaching experiments carried out in absence of $\mathrm{HgCl}_{2}$. The results obtained for two different soils are presented in Table 3. The biodegradation level of the leached PAH was dependant both upon the capacity of the microflora to degrade PAH and upon the bioavailable PAH. The physiological state of the microflora was also crucial because of the relatively short leaching time (24 hours). For instance the microflora present in soil SA was able to mineralise up to 5-ring PAH (data not shown), but in the biotic leachate only naphthalene was degraded. In fact, this microflora required a minimum adaptation time of two days to be able to degrade 3- and 4-ring PAH (data not shown). The microflora of soil
G2 was able to significantly degrade 3-ring PAH during the leaching experiments (Table 3).

\section{DISCUSSION}

\subsection{Monoaromatic Hydrocarbons}

The hydrocarbon composition and the electron acceptors indicate that biodegradation and dilution mechanisms are both contributing to natural attenuation along the first 700 meters of the plume. Beyond this first zone, lateral water fluxes arriving in the thalweg increasingly contributed to dilution effects and thus provided electron acceptors, both leading to an extensive hydrocarbon disappearance in the plume.

Biodegradation experiments involving the indigenous microflora were performed in laboratory. The biodegradation capacity determined is in good agreement with the disappearance of hydrocarbons in the first zone of the plume. Some major compounds such as 1,3,5 trimethylbenzene, 1-methyl, 2-ethylbenzene, 1,2,3 trimethylbenzene and $n$-propylbenzene appeared to be more recalcitrant to biodegradation under conditions limited by electron acceptors and their disappearance was partly related to dilution along the plume length.

The important upwelling events of the groundwater table occurring in this fractured chalk site sporadically favour an important transfer of hydrocarbons from the weakly weathered source to the aquifer. Nevertheless, the dissolved 
TABLE 2

PAH concentrations in a groundwater originating form a former gas plant without and with a filtration on a regenerated cellulose membrane. Samples from two monitoring wells (MW1 and MW2)

\begin{tabular}{|c|c|c|c|c|c|c|c|c|}
\hline & \multicolumn{8}{|c|}{ Concentrations $(\mu \mathrm{g} / \mathrm{l})$} \\
\hline & \multicolumn{4}{|c|}{ MW1 } & \multicolumn{4}{|c|}{ MW2 } \\
\hline & \multicolumn{2}{|c|}{ non filtrated } & \multicolumn{2}{|c|}{ filtrated } & \multicolumn{2}{|c|}{ non filtrated } & \multicolumn{2}{|c|}{ filtrated } \\
\hline Naphthalene & 8251 & & 7785 & & 2814 & & 2684 & \\
\hline Acenaphthylene & 156 & $(1.4)$ & 138 & (2) & 136 & $(0.9)$ & 132 & (6) \\
\hline Acenaphthene & 224 & (4) & 189 & (4) & 30 & $(0.1)$ & 27 & $(0.8)$ \\
\hline Fluorene & 171 & (2) & 111 & $(1.0)$ & 70 & $(0.8)$ & 64 & $(0.2)$ \\
\hline Phenanthrene & 220 & (3) & 125 & (2) & 66 & $(0.1)$ & 59 & (2) \\
\hline Anthracene & 25 & $(0.5)$ & 5.0 & $(0.1)$ & 4.7 & $(0.0)$ & 4.0 & $(0.1)$ \\
\hline Fluoranthene & 33 & $(0.7)$ & 12.9 & (3) & 7.6 & $(0.0)$ & 5.4 & $(0.6)$ \\
\hline Pyrene & 22 & $(0.3)$ & 5.5 & $(0.8)$ & 9.7 & $(0.3)$ & 6.7 & $(0.9)$ \\
\hline Benz(a)anthracene & 4.5 & $(0.3)$ & 0.01 & $(0.0)$ & 0.52 & $(0.0)$ & 0.06 & $(0.0)$ \\
\hline Chrysene & 3.4 & $(0.1)$ & 0.01 & $(0.0)$ & 0.29 & $(0.0)$ & 0.02 & $(0.0)$ \\
\hline Benzo(b)fluoranthene & 1.3 & $(0.1)$ & 0.00 & $(0.0)$ & 0.22 & $(0.0)$ & 0.01 & $(0.0)$ \\
\hline Benzo(k)fluoranthene & 0.6 & $(0.0)$ & 0.00 & $(0.0)$ & 0.07 & $(0.0)$ & 0.00 & $(0.0)$ \\
\hline Benzo(a)pyrene & 0.8 & $(0.7)$ & 0.00 & $(0.0)$ & 0.19 & $(0.0)$ & 0.00 & $(0.0)$ \\
\hline Dibenz(a.h)anthracene & 0.1 & $(0.1)$ & 0.00 & $(0.0)$ & 0.01 & $(0.0)$ & 0.00 & $(0.0)$ \\
\hline Benzo(g.h.i)perylene & 0.3 & $(0.0)$ & 0.00 & $(0.0)$ & 0.02 & $(0.0)$ & 0.00 & $(0.0)$ \\
\hline Indeno(c.d)pyrene & 1.6 & $(0.4)$ & 0.00 & $(0.0)$ & 0.00 & $(0.0)$ & 0.00 & $(0.0)$ \\
\hline Sum of 16 EPA PAH & \multicolumn{2}{|c|}{9114} & \multicolumn{2}{|c|}{8373} & \multicolumn{2}{|c|}{3139} & \multicolumn{2}{|c|}{2983} \\
\hline
\end{tabular}

(standard deviation of triplicates)

TABLE 3

PAH concentrations in leachates from soil samples originating from former gas plant sites SA and G2,

both leachates prepared in absence and in presence of $1 \mathrm{~g} / \mathrm{l}$ of $\mathrm{HgCl}_{2}$

\begin{tabular}{l|cc|cc}
\hline \multirow{2}{*}{} & \multicolumn{4}{c}{ Concentrations $(\mu \mathrm{g} / \mathrm{l})$} \\
\cline { 2 - 5 } & \multicolumn{2}{|c|}{ Soil SA } & \multicolumn{2}{c}{ Soil G2 } \\
\cline { 2 - 5 } & no $\mathrm{HgCl}_{2}$ & $+\mathrm{HgCl}_{2}$ & no $\mathrm{HgCl}_{2}$ & $+\mathrm{HgCl}_{2}$ \\
\hline Naphthalene & 803 & 5059 & 3 & 31 \\
Sum of 3-ring PAH & 488 & 546 & 83 & 320 \\
Sum of 4-ring PAH & 38.3 & 42.0 & 29.1 & 32.7 \\
Sum of 5- and 6-ring PAH & 0.63 & 0.68 & 0.25 & 0.08 \\
\hline Sum of the 16 EPA PAH & 1330 & 5648 & 115.2 & 384.4 \\
\hline
\end{tabular}

hydrocarbons monitored in the aquifer over several years indicate that the plume is not expanding despite the hydrogeological characteristics of this site. As a consequence, the natural attenuation illustrated in this work clearly contributes to limit the extension of the plume.

\subsection{Polyaromatic Hydrocarbons}

Polycyclic aromatic hydrocarbons are persistent organic pollutants. Even if biological treatments are an increasingly popular alternative for the decontamination of PAHcontaminated MGP soils, field experiments have shown that they are not always very successful. High PAH concentrations are often found, mainly sequestered in the coal tar matrix. Moreover, the fate and behaviour of PAH in the soil depends on complex phenomena in which natural attenuation takes an important place. In all these situations of natural or active remediation, the potential of PAH transfer may be variable and a critical question is to estimate the mobility of the PAH present in the coal tar matrix.

PAH concentrations in leachates are representative of the maximal potential for transfer to water. In both soil leaching experiments and groundwater originating from former MGP sites, the PAH appeared to be present as dissolved compounds 
or strongly bound to colloidal and coarse particles. The conclusion of this work has far reaching implications on the risk assessment of contaminated MGP sites since it contributes to identification of the physical states of the PAH in the groundwater.

\section{CONCLUSION}

These results highlight for both type of hydrocarbon contamination: monoaromatic and polyaromatic the importance of understanding the physical state of the contamination in the groundwater.

For the monoaromatic hydrocarbon contamination, the reproducibility in the laboratory of the hydrocarbon transfer from the oil phase to the aqueous phase in the field helps for understanding the transfer mechanisms occurring in situ. Thus it allows reliable biodegradation protocols to be established and gives solid information on effective natural attenuation. This analytical approach is suitable for following the biodegradation processes of components present in the water with concentration ranging from $\mu \mathrm{g} / \mathrm{l}$ to several $\mathrm{mg} / \mathrm{l}$. Biodegradable and recalcitrant compounds can be identified.

For polyaromatic hydrocarbon, the establishment of a representative aqueous transfer is a critical step for evaluating the risk associated with a soil contamination. The data presented on this subject show that the most important point either for laboratory or fieldwork is to avoid any artefacts such as biodegradation or the presence of coarse particles.

\section{REFERENCES}

Bethmann, D., Stieber, M., Brauch, H.J. and Blankenhorn, I. (1996) Optimierung des Elutionsverfahren nach DEV S4 zur Beurteilung von Grundwassergefährdungen durch lipophile Organika aus Altlasten oder Schadensfällen. In: $G D C H$ Jahrestagung, 7/10/96-10/10/96, Ulm, Germany.
Chang, M.K., Voice, T.C. and Criddle C.S. (1993) Kinetics of Competitive Inhibition and Cometabolism in the Biodegradation of Benzene, Toluene and Xylene. Water Sci. Technol., 20, 505-507.

Haeseler, F., Blanchet, D., Druelle, V., Werner, P. and Vandecasteele, J.P. (a) (1999) Analytical Characterization of Soils from Former Manufactured Gas Plants. Environ. Sci. Technol., 33, 825-830.

Haeseler, F., Blanchet, D., Druelle, V., Werner, P. and Vandecasteele, J.P. (b) (1999) Ecotoxicological Assessment of Former Manufactured Gas Plants Soils: Bioremediation Potential and Pollutant Mobility. Environ. Sci. Technol., 33, 4379-4384.

Keith, L.H. and Telliard, W.A. (1979) Priority Pollutants. I: A Perspective Review. Environ. Sci. Technol., 13, 416-423.

Kramer, P.G.N. and van der Heijden, C.A. (1990) Polycyclic Aromatic Hydrocarbons (PAH): Carcinogenicity Data and Risk Extrapolations. In: Environmental Topic 1, Rose, J. (ed), Gordon and Breach Science Publishers.

Luthy, R.G., Ramaswami, A. Ghoshal, S. and Merkel, W. (1993) Interfacial Films in Coal Tar Non Aqueous-Phase Liquid-Water Systems. Environ. Sci. Technol., 27, 2914-2917.

Oh, Y.S., Shareefdeen, Z., Baltzis, B.C. and Bartha, R. (1994) Interactions between Benzene and p-Xylene (BTEX) during their Biodegradation. Biotechnol. Bioeng., 44, 5336538.

Pawliszyn, J. (1999) Applications of Solid Phase Microextraction. The Royal Society of Chemistry, ISBN: 0854045252.

Rabus, R. and Widdel, F. (1995) Anaerobic Degradation of Ethylbenzene and Other Aromatics Hydrocarbons by New Denitrifying Bacteria. Arch Microbiol., 163, 96-103.

Solano-Serena, F., Marchal, R., Ropars, M., Lebeault, J.M. and Vandecasteele, J.P. (1999) Biodegradation of Gasoline: Kinetics, Masse Balance and Fate of Individal Hydrocarbons. J. Appl. Microbiol., 86, 1008-1016.

Tiehm, A., Stieber, M., Werner, P. and Frimmel, F.H. (1997) Surfactant-Enhanced Mobilization and Biodegradation of Polycyclic Aromatic Hydrocarbons in Manufactured Gas Plant Soil. Environ. Sci. Technol., 31, 2570.

Van Hamme, J.D., Singh, A. and Ward, O.P. (2003) Recent Advances in Petroleum Microbiology. Microbiol. Molecul. Biol Rev., 67, 503-549.

Widdel, F. and Rabus, R. (2001) Anaerobic Biodegradation of Saturated and Aromatic Hydrocarbons. Curr. Opin. Biotechnol., 12, 259-276.

Final manuscript received in May 2005 